\title{
Poultry Ownership Associated with Increased Risk of Child Diarrhea: Cross-Sectional Evidence from Uganda
}

\author{
Ayse Ercumen, ${ }^{1 \star}$ Chris Prottas, ${ }^{2}$ Angela Harris, ${ }^{3}$ Angelique Dioguardi, ${ }^{4}$ Greg Dowd, ${ }^{5}$ and Raymond Guiteras ${ }^{5}$ \\ ${ }^{1}$ Forestry and Environmental Resources, North Carolina State University, Raleigh, North Carolina; ${ }^{2}$ The Water Trust, New York, New York; ${ }^{3}$ Civil, \\ Construction and Environmental Engineering, North Carolina State University, Raleigh, North Carolina; ${ }^{4}$ The Water Trust, Kampala, Uganda; \\ ${ }^{5}$ Agricultural and Resource Economics, North Carolina State University, Raleigh, North Carolina
}

\begin{abstract}
Domestic animals have been associated with enteric infections in young children and can also be carriers of respiratory viruses. We conducted a cross-sectional assessment of health outcomes in children aged $<5$ years associated with animal presence among 793 rural households in Uganda. We recorded the 2-week prevalence of diarrhea and respiratory infections in children, and the number of cows, poultry, sheep/goats, and pigs in the household. We used generalized linear models with robust standard errors to estimate the prevalence ratio (PR) for diarrhea and respiratory infections associated with households owning the above- versus below-median number of animals. We conducted unadjusted and adjusted analyses controlling for socioeconomic, water, sanitation, and hygiene indicators. Children in households with the above-median number $(>5)$ of poultry had $83 \%$ higher diarrhea prevalence than those with $\leq 5$ poultry (adjusted PR $=1.83$ [1.04, 3.23], $P=0.04$ ). Children in households with the above-median number $(>2)$ of cows had $48 \%$ lower prevalence of respiratory infection than those with $\leq 2$ cows (adjusted $P R=0.52[0.35,0.76], P<0.005$ ). There were no other significant associations between domestic animals and child health. Studies should assess if barring chickens from indoor living quarters and sanitary disposal of chicken and other animal feces can reduce childhood zoonotic infections.
\end{abstract}

\section{INTRODUCTION}

Fecal contamination from animal sources is increasingly recognized as a risk factor for enteric infections among young children in low-income countries, where domestic animals are often kept in close proximity to living quarters. ${ }^{1}$ Molecular microbial source-tracking methods that allow differentiating between contamination of human versus animal origin have revealed widespread presence of animal fecal markers in the domestic environment in low-income countries. ${ }^{2-4}$ A study in India found that animal fecal markers detected in stored drinking water and on caregiver and child hands was associated with an over 4-fold increase in the odds of diarrhea in children aged $<5$ years. ${ }^{5}$ Two of the six leading pathogens associated with moderate-to-severe diarrhea in children in the Global Enteric Multicenter Study (Cryptosporidium and Campylobacter) have animal hosts. ${ }^{1,6,7}$ On the other hand, an analysis of demographic health survey data from 30 countries in subSaharan Africa did not find an association between animal ownership and child diarrhea but found slightly increased risk of child mortality associated with animal ownership; the study also revealed significant heterogeneity between countries. ${ }^{8}$

It is possible that different domestic animals (e.g., ruminant versus avian) vary in the level of human health risk they pose as they are hosts to different zoonotic pathogens. ${ }^{9}$ For example, poultry and cattle are carriers of Campylobacter and Salmonella, but cattle also carry Escherichia coli 0157: $\mathrm{H} 7$ and Cryptosporidium..$^{10-12}$ A systematic review and meta-analysis found more clear relationships between animal exposure and enteric infections when a causal pathogen was identified and specific animal-pathogen pairs were investigated; the strongest relationship was between Campylobacter and poultry, with an almost 3-fold increase in the

\footnotetext{
*Address correspondence to Ayse Ercumen, Forestry and Environmental Resources, North Carolina State University, 2225 Jordan Hall Addition, 2720 Faucette Dr., Raleigh, NC 27695. E-mail: aercume@ ncsu.edu
}

odds of Campylobacter infection associated with poultry exposure. ${ }^{13}$

Most studies of child exposure to domestic animals to date have focused on enteric infections. Chickens can transmit respiratory infections to humans. ${ }^{14-16}$ In addition, respiratory infections in children have been linked to diarrheal episodes. Malnutrition, which can result from diarrhea, is a risk factor for acute lower respiratory infections, and strains on the body from diarrhea, such as stress on the immune system and loss of micronutrients, can also put children at increased risk of respiratory infection. ${ }^{17}$ Recent diarrheal episodes have been associated with increased risk of pneumonia and acute lower respiratory infections among young children. ${ }^{17-19}$ On the other hand, animal ownership can improve the nutritional status, both through consumption of nutrient-rich animal-based foods or through income generation and consequently increased purchasing power for food items. ${ }^{20}$ Improved nutrition can, in turn, help fight off infections by boosting immune function. ${ }^{21}$ We conducted an analysis of the relationship between ownership of different domestic animals (cows, poultry, and sheep/goats) and diarrhea and respiratory infection in children aged $<5$ years among rural households in Uganda.

\section{MATERIALS AND METHODS}

We used data from an existing cross-sectional survey conducted in April 2018 among 1,235 households in 22 villages in Kiryandongo and Masindi districts of Uganda. The participants were selected for the survey based on their anticipated participation in an upcoming water, sanitation, and hygiene program implemented by the Water Trust. The selection criteria included that the communities were rural and had low levels of reliable water access and sanitation. For our analysis, we excluded households with no children aged $<5$ years, yielding a sample size of 793 households with a total of 1,336 children aged $<5$ years.

Enumerators hired and trained by a third-party monitoring and evaluation agency, Lida Africa, visited participants in their 
homes to conduct a structured questionnaire and spot-check observations. They recorded the caregiver-reported 2-week prevalence of diarrhea (defined as three loose, watery, or bloody stools in a 24-hour period) and respiratory infections in children aged $<5$ years. They also recorded the self-reported number of cows, poultry, sheep/goats, and pigs owned by the household. Enumerators also collected self-reported data on potential confounding factors such as demographic and socioeconomic indicators (the number of people living in the household, whether all school-aged children are attending school, whether the female household head/spouse can read and write, and main fuel type used for cooking), household assets (whether household members own a radio, mobile phone(s), and at least one pair of shoes for every member), and water, sanitation, and hygiene indicators (water source type, functionality and distance, latrine presence and type, and participants' reported knowledge about key times for handwashing). We augmented the self-reported questionnaire data with spot-check observations on water, sanitation, hygiene, and socioeconomic indicators; spot checks during unannounced visits can provide a rapid and unbiased method to capture day-to-day household practices and conditions. ${ }^{22}$ Enumerators observed the household's handwashing facility to check for the presence of water and soap, inspected the compound for human and animal feces in the living area for young children, and observed the materials of the walls and roof, and the ventilation status of the kitchen.

To quantify households' socioeconomic status, we calculated a poverty probability index $\left(\mathrm{PPI}^{\circledR}\right)$ that has been specifically developed and locally validated for the Ugandan setting based on data from the 2012 to 2013 National Household Survey conducted by the Uganda Bureau of Statistics. ${ }^{23}$ The PPI estimates the probability that a household is below the poverty line based on 10 questions on household assets and sociodemographic characteristics, including the number of people living in the household; whether all school-aged children are attending school; whether the female head/spouse can read and write; whether household members own a radio, mobile phone(s), and at least one pair of shoes for every member; the materials of the walls and roof; main fuel type used for cooking; and the type of toilet used by the household. We also calculated the total assets of each household by summing up their reported savings, the reported value any businesses owned by the household, and the estimated value of any owned land and domestic animals. We estimated the value of an acre of land at 2,000,000 Ugandan shillings (USD 527), the value of a cow at 900,000 shillings (USD 237), the value of a pig at 500,000 shillings (USD 132), the value of sheep/goats at 150,000 shillings (USD 40), and the value of a chicken at 30,000 shillings (USD 8), based on the local market prices at the time of the study.

We estimated the prevalence ratio (PR) for diarrhea and respiratory infection in children aged $<5$ years associated with households owning the above- versus below-median number of any animal, cows, poultry, and sheep/goats. We selected this exposure definition as it captures a higher exposure representing what is a large number of animals in this specific study population, and it also divides the dataset into optimally sized exposure groups to maximize statistical power to detect between-group differences. In addition, we also estimated the PR associated with increasing number of animals owned (i.e., PR for each additional cow and sheep/goat and for every 10 additional chickens/birds). We did not estimate PRs for pig ownership because of the small number of households owning pigs. We estimated PRs using generalized linear models with a Poisson error distribution with a log link function and robust standard errors accounting for clustering of health outcomes within study villages. ${ }^{24,25}$ We estimated unadjusted PRs as well as adjusted PRs controlling for socioeconomic, water, sanitation, and hygiene indicators. We considered the following potential confounders: village of residence; total value of assets; PPI score (which includes sanitation access); improved water access; water source functionality and distance; handwashing reported before food preparation, after defecation, after handling feces, and after handling animals; and (for respiratory infection) ventilation status of the kitchen. We included all covariates that showed an association with the outcome of interest at the $P<0.2$ level in final multivariable models. ${ }^{26}$ To further assess potential confounding by socioeconomic status, we investigated the relationship between animal ownership and socioeconomic status by comparing the number of animals owned across PPI quartiles with oneway analysis of variance (ANOVA). To assess exposure to animal feces as an intermediate outcome, we conducted a $x^{2}$ test to compare the prevalence of observed feces in the living area between households with the above- versus belowmedian number of animals. A checklist on study elements has been provided as per the Strengthening the Reporting of Observational Studies in Epidemiology (STROBE) guidelines (see Supplemental Text 1). ${ }^{27}$

The sample size for our analysis was determined by the number of households with available survey data and a child aged $<5$ years. Post hoc calculations of minimum detectable effect based on our recorded 2-week prevalence of diarrhea and respiratory infections indicated that our sample size of 1,336 children would allow $80 \%$ power to detect a $62 \%$ relative change in diarrhea prevalence and a $50 \%$ relative change in respiratory infection prevalence between children living in households with the above- versus below-median number of animals, with a two-sided $\alpha$ of 0.05 and an intracluster correlation coefficient of 0.005 for children in the same village. ${ }^{28}$

Ethics. The data used for this analysis were collected to serve as baseline for a programmatic evaluation by the Water Trust, and the analysis was conducted using de-identified data. The reported analysis was therefore determined to be exempt from ethical review by the human subjects committee of North Carolina State University. Verbal informed consent was obtained before the administration of each survey.

\section{RESULTS}

Household characteristics. Approximately $70 \%$ of households had access to an improved water source, with approximately $50 \%$ of households drawing water from a tubewell or borehole (Table 1). Three quarters of households reported that their main water point was at least partly functional, and half had their main water point less than $0.5 \mathrm{~km}$ away. Approximately $80 \%$ of households owned a latrine; more than $90 \%$ of latrines were uncovered pit latrines. The vast majority (97\%) of participants listed "before eating" as a key moment for handwashing, and $51 \%$ listed "after defecating," whereas $<25 \%$ of participants listed "before preparing food" as a key handwashing moment, and $<10 \%$ listed "after handling child feces" or "after working with animals." Only $2 \%$ of participants had a designated handwashing facility 
TABLE 1

Demographic, socioeconomic, and water, sanitation, and hygiene indicators $(N=793)$

\begin{tabular}{|c|c|}
\hline & $\%(n)$ \\
\hline \multicolumn{2}{|l|}{ Demographics and socioeconomics } \\
\hline $\begin{array}{l}\text { Oldest female head/spouse can read and write with } \\
\text { understanding in any language }\end{array}$ & $38.3(302)$ \\
\hline \multicolumn{2}{|l|}{ Wall material } \\
\hline Unburnt bricks with mud, mud and poles, or other & $69.1(548)$ \\
\hline $\begin{array}{l}\text { Unburnt bricks with cement, wood, tin/iron sheets, } \\
\text { concrete/stones, burnt stabilized bricks, or } \\
\text { cement blocks }\end{array}$ & $30.9(245)$ \\
\hline \multicolumn{2}{|l|}{ Roof material } \\
\hline Thatch, banana leaves/fibers, grass papyrus, or tin & $65.1(516)$ \\
\hline Iron sheets, concrete, tiles, asbestos, or other & $34.9(277)$ \\
\hline \multicolumn{2}{|l|}{ Main fuel used for cooking } \\
\hline Firewood, cow dung, or grass (reeds) & $92.2(731)$ \\
\hline $\begin{array}{l}\text { Charcoal, paraffin stove, gas, biogas, electricity, or } \\
\text { other }\end{array}$ & $7.8(62)$ \\
\hline \multicolumn{2}{|l|}{$\begin{array}{l}\text { Number of mobile phones owned by household } \\
\text { members (at household level) }\end{array}$} \\
\hline None & $47.7(378)$ \\
\hline One & $40.0(317)$ \\
\hline Two or more & $12.4(98)$ \\
\hline Household owns radio & $66.7(529)$ \\
\hline $\begin{array}{l}\text { Every member of the household has at least one pair } \\
\text { of shoes }\end{array}$ & $73.1(580)$ \\
\hline \multicolumn{2}{|l|}{ Water, sanitation, and hygiene indicators } \\
\hline \multirow{2}{*}{\multicolumn{2}{|c|}{$\begin{array}{l}\text { Water source } \\
\text { Improved }\end{array}$}} \\
\hline & \\
\hline Tube well/borehole & $53.0(420)$ \\
\hline Protected dug well/shallow well & $9.1(72)$ \\
\hline Protected spring & $5.7(45)$ \\
\hline Public tap/standpipe & $3.4(27)$ \\
\hline Rainwater collection & $0.9(7)$ \\
\hline \multicolumn{2}{|l|}{ Unimproved } \\
\hline Unprotected source/surface water & $28.0(222)$ \\
\hline Main water point functional or partly functional & $75.9(602)$ \\
\hline Main water source $<0.5 \mathrm{~km}$ away & $46.1(364)$ \\
\hline Time to fetch water $<30$ minutes roundtrip & $36.6(290)$ \\
\hline Household owns a latrine & $79.7(629)$ \\
\hline \multicolumn{2}{|l|}{ Latrine type } \\
\hline Uncovered pit latrine without superstructure & $35.6(224)$ \\
\hline Uncovered pit latrine with superstructure & $55.0(346)$ \\
\hline Covered pit latrine without superstructure & $4.8(30)$ \\
\hline Covered pit latrine with superstructure & $2.5(16)$ \\
\hline Ventilated improved pit latrine & $2.1(13)$ \\
\hline $\begin{array}{l}\text { Household has handwashing facility with water and } \\
\text { soap }\end{array}$ & $1.9(12)$ \\
\hline \multicolumn{2}{|l|}{$\begin{array}{l}\text { Respondent-reported key moments for handwashing } \\
\text { include }\end{array}$} \\
\hline Before eating & $97.0(769)$ \\
\hline Before preparing food & $21.2(168)$ \\
\hline After defecating & $51.0(404)$ \\
\hline After handling child feces & $7.9(63)$ \\
\hline After handling animals & $7.8(62)$ \\
\hline $\begin{array}{l}\text { Animal or human feces observed on the ground inside } \\
\text { the home }\end{array}$ & $16.9(134)$ \\
\hline
\end{tabular}

with water and soap observed. Approximately $17 \%$ of households had animal or human feces observed in young children's living area. Cow dung was used as fuel; $92 \%$ of households reported using rudimentary materials (firewood, cow dung, or grass/reeds) as their main fuel for cooking.

Animal ownership. Approximately two-thirds of households owned at least one animal, with 17\% owning cows, 57\% owning chickens/birds, 32\% owning sheep/goats, and 3\% owning pigs (Table 2). Households with animals owned a median of two cows (interquartile range [IQR]: 1-4, range: 1-60), five chickens/birds (IQR:3-8, range: 1-100), two sheep/goats (IQR: 1-3, range: 1-33), and two pigs (IQR: 1-3, range: 1-4). Animal ownership was positively associated with socioeconomic status as measured by the PPI; the number of animals owned progressively increased from the bottom socioeconomic quartile in our dataset to the top quartile $(P$-value $=0.03)$ (Table 3$)$. This was mostly driven by poultry; the bottom socioeconomic quartile owned an average of 2.7 chickens/birds, whereas the top quartile owned an average of 4.8 chickens/birds $(P$-value $=0.01)$. There was no association between socioeconomic quartile and the number of cows, sheep/goats, or pigs owned $(P$-value $>0.05)$. The prevalence of observed feces within the living area was $21 \%$ among households with an abovemedian number of animals versus $15 \%$ among those with a below-median number of animals $\left(x^{2} P\right.$-value $\left.=0.03\right)$.

Diarrhea and respiratory infection in children aged $<5$ years. The caregiver-reported 2-week prevalence of symptoms among children aged $<5$ years was $5.2 \%$ for diarrhea and $8.5 \%$ for respiratory infection. In unadjusted bivariate analyses, children in households with the above-median number of cows had a lower prevalence of diarrhea and respiratory infection, and children in households with the above-median number of poultry had a lower prevalence of respiratory infection (Table 4). In adjusted models controlling for potential confounders, children in households that owned more than the median number $(>5)$ of poultry had $83 \%$ higher diarrhea prevalence than those with $\leq 5$ poultry (adjusted $\mathrm{PR}=1.83(1.04,3.23), P$-value $=0.04$, Table 4). Children in households with more than the median number ( $>2$ ) of cows had $48 \%$ lower prevalence of respiratory infection than those with $\leq 2$ cows (adjusted PR $=0.52(0.35$, $0.76), P$-value $<0.005$, Table 4). The analysis using the number of animals as the independent variable yielded similar effect estimates. In unadjusted analyses, children exposed to increasing number of cows had a lower prevalence of diarrhea and respiratory infection, whereas children exposed to increasing number of poultry had a lower prevalence of respiratory infection (Table 5). In adjusted models, each additional cow was associated with $19 \%$ lower prevalence of respiratory infection (adjusted PR $=0.81(0.66,0.98), P$-value $=0.03$, Table 5). The number of poultry was not significantly associated with diarrhea, but the direction and magnitude of the effect estimate suggested an increase in diarrhea prevalence associated with every additional 10 chickens/birds (adjusted PR = $1.29[0.85,1.95], P$-value $=0.23$, Table 5). There were no other significant associations between animals and health outcomes in adjusted analyses.

\section{DISCUSSION}

We found higher risk of diarrhea associated with increasing exposure to poultry in the household compound but not to other animals. Our findings support a growing body of evidence that chicken exposure is a risk factor for childhood enteric infections. The presence of chickens has been linked to increased risk of Campylobacter diarrhea in children in Peru. ${ }^{29}$ A molecular analysis of child and chicken feces in Ecuador detected Campylobacter spp. in 76\% of chicken feces, and Campylobacter jejuni genotypes associated with chickens were more frequently isolated from children's feces than genotypes associated with other domestic animals, implicating chickens as the primary agent of zoonotic Campylobacter transmission. ${ }^{30}$

In our study setting, chickens are raised for domestic consumption and local sale of eggs and meat; only a small minority 
TABLE 2

Animal ownership $(N=793)$

\begin{tabular}{|c|c|c|}
\hline & Households owning animal, \% (n) & Number of animals ${ }^{*}$, median (interquartile range) \\
\hline Any animal & $64.8(514)$ & $6(3-10)$ \\
\hline Cows & $17.3(137)$ & $2(1-4)$ \\
\hline Poultry & 56.6 (449) & $5(3-8)$ \\
\hline Sheep/goats & $31.8(252)$ & $2(1-3)$ \\
\hline Pigs & $3.3(26)$ & $2(1-3)$ \\
\hline
\end{tabular}

${ }^{\star}$ Among households that have at least one animal.

of households have concentrated feeding operations, whereas most households raise free-range local breed chickens (Masindi District Animal Husbandry Officer, personal communication). Although antibiotics and vaccines are used in the concentrated feedlots, most households do not use chemotherapeutic treatment for their chickens (Masindi District Animal Husbandry Officer, personal communication). The Water Trust field staff report that, in our study setting, chickens are not kept in a defined space and are permitted to wander in and out of the house (whereas cows, sheep, goats, and pigs are more likely to be secured, or, if not secured, not permitted to enter the living area), and some families also sleep with their chickens inside their home to reduce the risk of theft. In addition, whereas cows can be relocated to other areas to graze, chickens typically remain in/near the compound and roam the compound area scavenging for food, scattering their feces in the process. As a consequence, it is possible that chicken feces are more prevalent in the compound environment than feces of other domestic animals. In a study in Bangladesh, $90 \%$ of households had chickens and $87 \%$ had chicken feces observed in the courtyard, whereas $69 \%$ of households had cows, but only $30 \%$ had cow feces in the courtyard. ${ }^{31}$

This is consistent with observational evidence of frequent child exposure to chicken feces from other studies. Observations in Peru and Zimbabwe have shown that young children touch and directly ingest chicken feces scattered in the compound. ${ }^{32,33}$ Although older children can also be exposed to animal feces while they help with animal husbandry chores, for children aged $<5$ years, it is likely that exposure primarily results from exploratory hand and mouth contact with feces and/or soil contaminated with feces. A study in Bangladesh has found the presence of chickens and chicken feces in the environment to be associated with increased $E$. coli contamination of courtyard soil, stored drinking water, and stored food; contamination associated with chickens was more pronounced than contamination associated with cows, goats, and sheep. ${ }^{31}$

Interventions to corral chickens in an attempt to reduce child exposure to chicken feces have not succeeded in reducing infections. In Peru, corralling chickens increased, rather than decreased, Campylobacter diarrhea in children compared with letting them free range. ${ }^{34} \mathrm{~A}$ study in Ethiopia found reduced child height-for-age Z-scores (HAZ) in households that corralled chickens but no associations between $\mathrm{HAZ}$ and other corralled animals; the overall chicken ownership, on the other hand, was associated with improved HAZ. ${ }^{35}$ An alternative to corralling chickens could be to provide designated hygienic play spaces for children that are kept free of animal feces. However, a recent study in Zimbabwe that provided plastic play mats for young children (among other water, sanitation, and hygiene interventions) did not reduce child diarrhea or improve growth. ${ }^{36}$

Even though cow dung was used as cooking fuel in study households, leading to potential contamination of caregiver hands, surfaces, and objects, the presence of cows was not associated with increased prevalence of diarrhea. On the other hand, collecting and setting aside cow dung to be used as fuel may reduce children's exposure to cow feces in the compound environment. Also, the typical practice of sundrying cow dung before use can inactivate pathogens through desiccation. ${ }^{10}$ The lack of association we observed between cows and other domestic animals (sheep and goats) and diarrhea is consistent with studies in India and Vietnam that found no relationship between cow exposure and child diarrhea, although the latter study also found no relationship between chicken exposure and diarrhea. ${ }^{37,38}$ It has also been suggested that animal contact can lead to protective immunity, counteracting the effect of zoonotic transmission of enteric pathogens. ${ }^{39}$

We found lower risk of respiratory infection in children associated with increasing exposure to cows. It is possible that cow ownership is associated with increased consumption of dairy products and consequently improved nutritional status. ${ }^{20}$ In our study setting, it is estimated that $90 \%$ of cows are raised for meat and $10 \%$ for dairy; among dairy cows, $90 \%$ of the milk is sold and the rest is reserved for domestic consumption (Masindi District Animal Husbandry Officer, personal communication). An analysis of demographic health survey data from sub-Saharan Africa found that 22 of the 30 countries included in the analysis showed a protective effect

TABLE 3

Animal ownership by categories of poverty probability index $(\mathrm{PPI})^{\star}(N=793)$

\begin{tabular}{clcccc}
\hline Mean number of animals (range) & Top quartile & Second quartile & Third quartile & Bottom quartile & ANOVA $P$-value \\
\hline Any animal & $6.8(0-103)$ & $5.5(0-48)$ & $5.2(0-33)$ & $4.3(0-61)$ & 0.03 \\
Cows & $1.0(0-60)$ & $0.7(0-15)$ & $0.4(0-8)$ & $0.7(0-30)$ \\
Poultry & $4.8(0-100)$ & $3.7(0-30)$ & $3.6(0-20)$ & $2.7(0-20)$ & 0.28 \\
Sheep/goats & $0.8(0-15)$ & $1.0(0-33)$ & $1.1(0-11)$ & $0.9(0-11)$ & 0.01 \\
Pigs & $0.1(0-4)$ & $0.1(0-4)$ & $0.1(0-2)$ & $0.0(0-2)$ & 0.09 \\
\hline
\end{tabular}

* Poverty probability index estimates the probability that a household is below the poverty line based on the number of people living in the household; whether all school-aged children are attending school; whether the female head/spouse can read and write; whether household members own a radio, mobile phone(s), and at least one pair of shoes for every member; the materials of the walls and roof; main fuel type used for cooking; and type of toilet used by the household. 
TABLE 4

Two-week prevalence of diarrhea and respiratory infection in children aged $<5$ years associated with owning the above- vs. below-median number of animals $(N=1,336)$

\begin{tabular}{|c|c|c|c|c|}
\hline & \multicolumn{2}{|c|}{ Unadjusted } & \multicolumn{2}{|c|}{ Adjusted $^{*}$} \\
\hline & $\mathrm{PR}(95 \% \mathrm{Cl})$ & $P$-value & PR $(95 \%$ Cl) & $P$-value \\
\hline \multicolumn{5}{|l|}{ Diarrhea } \\
\hline Animals (> 6 vs. $\leq 6)$ & $0.86(0.45,1.62)$ & 0.63 & $1.18(0.57,2.44)$ & 0.65 \\
\hline Cows $(>2$ vs. $\leq 2)$ & $0.27(0.08,0.98)$ & 0.05 & $0.41(0.08,2.09)$ & 0.28 \\
\hline Poultry (> 5 vs. $\leq 5)$ & $1.09(0.58,2.05)$ & 0.79 & $1.83(1.04,3.23)$ & 0.04 \\
\hline Sheep/goats (> 2 vs. $\leq 2)$ & $0.48(0.14,1.59)$ & 0.23 & $0.41(0.13,1.32)$ & 0.14 \\
\hline \multicolumn{5}{|l|}{ Respiratory infection } \\
\hline Animals $(>6$ vs. $\leq 6)$ & $0.37(0.21,0.64)$ & $<0.005$ & $0.56(0.32,0.99)$ & 0.05 \\
\hline Cows $(>2$ vs. $\leq 2)$ & $0.51(0.28,0.92)$ & 0.02 & $0.52(0.35,0.76)$ & $<0.005$ \\
\hline Poultry (> 5 vs. $\leq 5)$ & $0.40(0.23,0.69)$ & $<0.005$ & $0.62(0.36,1.07)$ & 0.09 \\
\hline Sheep/goats (>2 vs. $\leq 2)$ & $0.93(0.46,1.84)$ & 0.83 & $1.31(0.75,2.27)$ & 0.34 \\
\hline
\end{tabular}

* We considered the following adjustment covariates: Village of residence; total value of assets; poverty score (which includes sanitation access); improved water access; water source functionality and distance; handwashing reported before food preparation, after defecation, after handling child feces, and after handling animals; and (for respiratory infection) ventilation status of the kitchen. Covariates associated with each outcome at $P<0.2$ level in bivariate assessment were included in the adjusted models.

of animal ownership against child stunting, indicating improved nutrition. ${ }^{8}$ Improved nutrition, in turn, can reduce the risk of respiratory infection. ${ }^{19}$

We found no increased risk of respiratory infections associated with poultry ownership even though birds are carriers of respiratory pathogens. ${ }^{40}$ Chickens have been associated with bird-to-human transmission of avian influenza, ${ }^{41}$ and elevated antibody titers for influenza $A$ viruses have been detected among agricultural workers and veterinarians exposed to chickens. ${ }^{14-16}$ Respiratory infections have strong seasonality with distinct winter peaks in temperate regions. ${ }^{42}$ In the tropics, where average temperatures are higher with less seasonal variation, the seasonality of respiratory viruses is less well defined. However, studies in the tropics have shown increases in respiratory infections associated with seasonal rainfall and humidity patterns. ${ }^{43-46}$ Seasonal trends and associations with rainfall have also been observed for enteric infections. ${ }^{47,48}$ Our study period in April coincided with the very beginning of the rainy season, which started in late April 2018 in our study area. It is possible that there were no major infections circulating during this month-long study window or that our study duration was not sufficiently long to capture trends in infection. Indeed, disease prevalence in our dataset was substantially lower than previously recorded in the study area. A 2017 survey in the same area found a 2-week prevalence of $11 \%$ for diarrhea and $25 \%$ for respiratory infection among children aged $<5$ years. ${ }^{49}$ The difference could be due to seasonal factors; the 2017 survey was conducted in December just at the beginning of the dry season and may therefore have a higher prevalence of illness from the wet season just ending then, whereas the current survey was conducted at the beginning of the rainy season and may reflect the lower infection prevalence of the dry season. A study conducted during a time of high-intensity transmission or over a long enough period to capture peaks in infection might be better poised to assess associations between animal exposure and infections.

Another limitation of our study is that we relied on caregiverreported recall of diarrhea and respiratory symptoms over a 2 -week period. Whereas reported symptoms could be inaccurate without a clinical diagnosis, self-reported health outcomes are commonly used in epidemiologic studies when clinically confirming infections is not feasible. In addition, although a 2-week recall could have inaccuracies compared with the commonly used shorter recall windows such as 1 week or 2 days, ${ }^{50,51}$ we expect any such inaccuracies to be non-differential with respect to animal ownership (i.e., we do not anticipate that animal ownership will affect the accuracy with which respondents report health endpoints). We therefore assume that any such non-differential misclassification of

TABLE 5

Two-week prevalence of diarrhea and respiratory infection in children aged $<5$ years associated with the number of animals owned $(N=1,336)$

\begin{tabular}{|c|c|c|c|c|}
\hline & & & & \\
\hline & PR $(95 \% \mathrm{Cl})$ & $P$-value & PR (95\% Cl) & $P$-value \\
\hline Diarrhea & & & & \\
\hline Animals & $0.73(0.45,1.17)$ & 0.19 & $0.96(0.64,1.46)$ & 0.86 \\
\hline Cows & $0.75(0.59,0.95)$ & 0.02 & $0.78(0.58,1.05)$ & 0.10 \\
\hline Poultry & $0.86(0.54,1.37)$ & 0.52 & $1.29(0.85,1.95)$ & 0.23 \\
\hline Sheep/goats & $0.86(0.71,1.04)$ & 0.12 & $0.89(0.76,1.05)$ & 0.17 \\
\hline Respiratory infe & & & & \\
\hline Animals & $0.55(0.32,0.93)$ & 0.03 & $0.70(0.42,1.18)$ & 0.18 \\
\hline Cows & $0.78(0.61,1.00)$ & 0.05 & $0.81(0.66,0.98)$ & 0.03 \\
\hline Poultry & $0.47(0.22,1.00)$ & 0.05 & $0.72(0.38,1.36)$ & 0.31 \\
\hline Sheep/goats & $0.93(0.79,1.10)$ & 0.40 & $1.00(0.90,1.12)$ & 0.97 \\
\hline
\end{tabular}

$\mathrm{PR}=$ prevalence ratio; $\mathrm{Cl}=$ confidence interval.

Prevalence ratio associated with each additional cow and sheep/goat, and every 10 additional animals and chickens.

† We considered the following adjustment covariates: village of residence; total value of assets; poverty score (which includes sanitation access); improved water access; water source functionality and distance; handwashing reported before food preparation, after defecation, after handling child feces, and after handling animals; and (for respiratory infection) ventilation status of the kitchen. Covariates associated with each outcome at $P<0.2$ level in bivariate assessment were included in the adjusted models. 
outcomes would bias our findings toward, rather than away, from the null. ${ }^{52}$ Future studies using shorter recall windows or using clinical specimens to ascertain infections may show more pronounced illness risk associated with chicken exposure. Reported diarrhea also does not differentiate between infections of bacterial, viral, or protozoan etiology. Since different domestic animals are carriers of different pathogens, clinically confirmed infections allowing investigation of pathogen-specific infections and specific animal-pathogen pairs would be expected to reveal clearer associations between animal ownership and health endpoints. ${ }^{13}$

In addition, reported diarrhea symptoms fail to take into account subclinical infections and asymptomatic pathogen carriage. A growing body of literature suggests widespread asymptomatic gut colonization with enteric pathogens among young children in low-income countries. ${ }^{53}$ A study in Bangladesh analyzed stool specimens from children aged $<1$ year with versus without symptomatic diarrhea using molecular methods and found that children with no diarrhea had three different pathogens detected in their stool on average, compared with five pathogens among children with diarrhea. ${ }^{54}$ Of the 29 pathogens the study investigated, only seven had a significantly higher prevalence in diarrheal versus non-diarrheal stool samples. ${ }^{54}$ Similarly, a study in Tanzania analyzed stool samples for 19 enteropathogens with molecular methods and found no difference between the number of pathogens detected and the prevalence of any given pathogen between stool samples from children with versus without diarrhea. ${ }^{55}$ The health implications of asymptomatic colonization and subclinical infections are not well understood. Chronic pathogen exposure can result in environmental enteric dysfunction, which is thought to contribute to growth faltering in children. ${ }^{56,57}$ Exposure to domestic animals was associated with markers of environmental enteric dysfunction in children in rural Bangladesh. ${ }^{58}$ Health endpoints that capture asymptomatic pathogen carriage and subclinical infections may allow more nuanced understanding of the health impact of domestic animal exposure among young children; future studies should collect and analyze clinical specimens to detect and quantify pathogen carriage.

Our analysis was observational and is susceptible to confounding, for example, by socioeconomic status, which is typically associated with animal ownership as well as disease prevalence. However, richer households in our dataset owned a larger number of birds such that any confounding from unmeasured socioeconomic factors would likely attenuate and not exaggerate the relationship we observed between poultry ownership and diarrhea. It is also possible that the lower prevalence of respiratory infection associated with increasing number of cows is due to residual confounding from unmeasured socioeconomic factors. However, we used a validated poverty index based on a comprehensive set of indicators to quantify and control for socioeconomic status in our models. Indeed, in unadjusted bivariate models, increasing exposure to cows was associated with a lower prevalence of diarrhea and respiratory infection, whereas increasing exposure to poultry was associated with a lower prevalence of respiratory infection. However, after adjusting for potential confounders including household assets and poverty index, the only negative association that remained significant was the one between cows and respiratory infection, suggesting that this could be a true protective effect.
In addition, there was no association between poverty quartile and the number of cows owned.

Finally, our sample size was limited by the number of households with available data, and our analysis was therefore powered for relatively large minimum detectable effects $(62 \%$ relative change in diarrhea prevalence and $50 \%$ relative change in respiratory infection prevalence between children in households with the above- versus below-median number of animals).

Our results indicate increased risk of diarrhea associated with poultry ownership. Although we expect our findings to be generalizable to other settings with similar animal husbandry practices, previous studies indicate substantial heterogeneity on the association between animal exposure and child health. Chickens can provide nutrient-dense foods and have been associated with improved growth in children. ${ }^{35}$ Therefore, it is important to identify strategies to reduce child exposure to chickens and their feces to mitigate the risk of infection while maintaining the nutritional benefits of poultry ownership. It has been suggested that failure to address animal feces can explain why sanitation interventions focused solely on isolating human feces have failed to significantly reduce child exposure to fecal contamination in studies to date ${ }^{59,60}$ Potential strategies to reduce child exposure to chicken feces could include not keeping chickens in the indoor living quarters and removal and sanitary disposal of chicken feces; studies should assess if these approaches reduce zoonotic infections among young children.

Received January 7, 2019. Accepted for publication December 10, 2019.

Published online January 20, 2020.

Acknowledgments: We thank the families who participated in the study for their time and contribution. We also thank David Okubal, Osbert Atwijukye, Geofrey Kusemererwa, and the rest of The Water Trust staff who supported data collection and community training and engagement following the survey. We likewise thank Lida Africa for conducting data collection.

Financial support: The collection of data used in this analysis was funded by Deerfield Foundation, Vibrant Village Foundation, the Water Project, Pace Family Foundation, One Day's Wages, and the International Foundation.

Authors' addresses: Ayse Ercumen, Forestry and Environmental Resources, North Carolina State University, Raleigh, NC, E-mail: aercume@ncsu.edu. Chris Prottas, The Water Trust, New York, NY, E-mail: cprottas@watertrust.org. Angela Harris, Civil, Construction and Environmental Engineering, North Carolina State University, Raleigh, NC, E-mail: aharris5@ncsu.edu. Angelique Dioguardi, The Water Trust, Kampala, Uganda, E-mail: Idioguardi@watertrust.org. Greg Dowd and Raymond Guiteras, Agricultural and Resource Economics, North Carolina State University, Raleigh, NC, E-mails: ggdowd@ncsu.edu and rpguiter@ncsu.edu.

This is an open-access article distributed under the terms of the Creative Commons Attribution (CC-BY) License, which permits unrestricted use, distribution, and reproduction in any medium, provided the original author and source are credited.

\section{REFERENCES}

1. Delahoy MJ, Wodnik B, McAliley L, Penakalapati G, Swarthout J, Freeman MC, Levy K, 2018. Pathogens transmitted in animal feces in low- and middle-income countries. Int $J$ Hyg Environ Health 221: 661-676.

2. Schriewer A, Odagiri M, Wuertz S, Misra PR, Panigrahi P, Clasen $T$, Jenkins MW, 2015. Human and animal fecal contamination of community water sources, stored drinking water and hands in rural India measured with validated microbial source tracking assays. Am J Trop Med Hyg 93: 509-516. 
3. Harris AR, Pickering AJ, Harris M, Doza S, Islam MS, Unicomb L, Luby S, Davis J, Boehm AB, 2016. Ruminants contribute fecal contamination to the urban household environment in Dhaka, Bangladesh. Environ Sci Technol 50: 4642-4649.

4. Boehm AB et al., 2016. Occurrence of host-associated fecal markers on child hands, household soil, and drinking water in rural Bangladeshi households. Environ Sci Technol Lett 3: 393-398.

5. Odagiri $\mathrm{M}$ et al., 2016. Human fecal and pathogen exposure pathways in rural Indian villages and the effect of increased latrine coverage. Water Res 100: 232-244.

6. Kotloff KL et al., 2013. Burden and aetiology of diarrhoeal disease in infants and young children in developing countries (the global enteric multicenter study, GEMS): a prospective, case-control study. Lancet 382: 209-222.

7. Liu $\mathrm{J}$ et al., 2016. Use of quantitative molecular diagnostic methods to identify causes of diarrhoea in children: a reanalysis of the GEMS case-control study. Lancet 388: 1291-1301.

8. Kaur M, Graham JP, Eisenberg JNS, 2017. Livestock ownership among rural households and child morbidity and mortality: an analysis of demographic health survey data from 30 subsaharan african countries (2005-2015). Am J Trop Med Hyg 96: 741-748.

9. Soller JA, Schoen ME, Bartrand T, Ravenscroft JE, Ashbolt NJ, 2010. Estimated human health risks from exposure to recreational waters impacted by human and non-human sources of faecal contamination. Water Res 44: 4674-4691.

10. Sobsey MD, Khatib LA, Hill VR, Alocilja E, Pillai S, 2001. Pathogens in animal wastes and the impacts of waste management practices on their survival, transport and fate. White Papers on Animal Agriculture and the Environment. Ames, IA: MidWest Plan Service (MWPS), lowa State University.

11. Fey PD, Safranek TJ, Rupp ME, Dunne EF, Ribot E, Iwen PC, Bradford PA, Angulo FJ, Hinrichs SH, 2000. Ceftriaxoneresistant Salmonella infection acquired by a child from cattle. N Engl J Med 342: 1242-1249.

12. Stanley K, Jones $K, 2003$. Cattle and sheep farms as reservoirs of Campylobacter. J Appl Microbiol 94: 104-113.

13. Zambrano LD, Levy K, Menezes NP, Freeman MC, 2014. Human diarrhea infections associated with domestic animal husbandry: a systematic review and meta-analysis. Trans $R$ Soc Trop Med Hyg 108: 313-325.

14. Myers KP, Setterquist SF, Capuano AW, Gray GC, 2007. Infection due to 3 avian influenza subtypes in United States veterinarians. Clin Infect Dis 45: 4-9.

15. Puzelli S, Di Trani L, Fabiani C, Campitelli L, De Marco MA, Capua I, Aguilera JF, Zambon M, Donatelli I, 2005. Serological analysis of serum samples from humans exposed to avian $\mathrm{H} 7$ influenza viruses in Italy between 1999 and 2003. J Infect Dis 192: 1318-1322.

16. Gray GC, McCarthy T, Capuano AW, Setterquist SF, Alavanja MC, Lynch CF, 2008. Evidence for avian influenza A infections among lowa's agricultural workers. Influenza Other Respir Viruses 2: 61-69.

17. Schmidt WP, Cairncross S, Barreto ML, Clasen T, Genser B, 2009. Recent diarrhoeal illness and risk of lower respiratory infections in children under the age of 5 years. Int J Epidemiol 38: 766-772.

18. Ashraf S, Huque MH, Kenah E, Agboatwalla M, Luby SP, 2013. Effect of recent diarrhoeal episodes on risk of pneumonia in children under the age of 5 years in Karachi, Pakistan. Int $J$ Epidemiol 42: 194-200.

19. Coles CL, Fraser D, Givon-Lavi N, Greenberg D, Gorodischer R, Bar-Ziv J, Dagan R, 2005. Nutritional status and diarrheal illness as independent risk factors for alveolar pneumonia. Am J Epidemiol 162: 999-1007.

20. Randolph TF, Schelling E, Grace D, Nicholson CF, Leroy JL, Cole DC, Demment MW, Omore A, Zinsstag J, Ruel M, 2007. Invited review: role of livestock in human nutrition and health for poverty reduction in developing countries. J Anim Sci 85: 2788-2800.

21. Dewey KG, Mayers DR, 2011. Early child growth: how do nutrition and infection interact? Matern Child Nutr 7 (Supp/ 3): 129-142.
22. Ruel MT, Arimond M, 2002. Spot-check observational method for assessing hygiene practices: review of experience and implications for programmes $J$ Health Popul Nutr 20: 65-76.

23. Schreiner M, 2015. Microfinance Risk Management. Uganda: Microfinance Risk Management, LLC. Available at: https:// www.povertyindex.org/country/uganda. Accessed October $11,2018$.

24. Zou G, 2004. A modified Poisson regression approach to prospective studies with binary data. Am J Epidemiol 159: 702-706.

25. Yelland LN, Salter AB, Ryan P, 2011. Performance of the modified poisson regression approach for estimating relative risks from clustered prospective data. Am J Epidemiol 174: 984-992.

26. Pocock SJ, Assmann SE, Enos LE, Kasten LE, 2002. Subgroup Analysis, covariate adjustment and baseline comparisons in clinical trial reporting: current practiceand problems. Stat Med 21: 2917-2930.

27. von Elm E, Altman DG, Egger M, Pocock SJ, Gøtzsche PC, Vandenbroucke JP, 2014. The strengthening the reporting of observational studies in epidemiology (STROBE) statement: guidelines for reporting observational studies. Int J Surg 12: 1495-1499.

28. Katz J, Carey VJ, Zeger SL, Sommer A, 1993. Estimation of design effects and diarrhea clustering within households and villages. Am J Epidemiol 138: 994-1006.

29. Grados O, Bravo N, Black RE, Butzler JP, 1988. Paediatric Campylobacter diarrhoea from household exposure to live chickens in Lima, Peru. Bull World Health Organ 66: 369-374.

30. Vasco K, Graham JP, Trueba G, 2016. Detection of zoonotic enteropathogens in children and domestic animals in a semirural community in Ecuador. Appl Environ Microbiol 82: 4218-4224.

31. Ercumen A et al., 2017. Animal feces contribute to domestic fecal contamination: evidence from $E$. Coli measured in water, hands, food, flies, and soil in Bangladesh. Environ Sci Technol 51: 8725-8734.

32. Ngure FM et al., 2013. Formative research on hygiene behaviors and geophagy among infants and young children and implications of exposure to fecal bacteria. Am J Trop Med Hyg 89: 709-716.

33. Marquis GS, Ventura G, Gilman RH, Porras E, Miranda E, Carbajal L, Pentafiel M, 1990. Fecal contamination of shanty town toddlers in households with non-corralled poultry, Lima, Peru. Am $J$ Public Health 80: 146-149.

34. Oberhelman RA, Gilman RH, Sheen P, Cordova J, Zimic M, Cabrera L, Meza R, Perez J, 2006. An intervention-control study of corralling of free-ranging chickens to control Campylobacter infections among children in a Peruvian periurban shantytown. Am J Trop Med Hyg 74: 1054-1059.

35. Headey D, Hirvonen K, 2016. Is exposure to poultry harmful to child nutrition? An observational analysis for rural Ethiopia. PLoS One 11: e0160590.

36. Humphrey JH et al., 2019. Independent and combined effects of improved water, sanitation, and hygiene, and improved complementary feeding, on child stunting and anaemia in rural Zimbabwe: a cluster-randomised trial. Lancet Glob Health 7: e132-e147.

37. Schmidt W-P, Boisson S, Routray P, Bell M, Cameron M, Torondel B, Clasen T, 2016. Exposure to cows is not associated with diarrhoea or impaired child growth in rural Odisha, India: a cohort study. Epidemiol Infect 144: 53-63.

38. Thiem VD, Schmidt W-P, Suzuki M, Tho LH, Yanai H, Ariyoshi K, Anh DD, Yoshida L-M, 2012. Animal Livestock and the risk of hospitalized diarrhoea in children under 5 years in Vietnam. Trop Med Int Health 17: 613-621.

39. Mayne DJ, Ressler K-A, Smith D, Hockey G, Botham SJ, Ferson MJ, 2011. A community outbreak of cryptosporidiosis in sydney associated with a public swimming facility: a case-control study. Interdiscip Perspect Infect Dis 2011: 341065.

40. World Health Organization, 2018. Influenza (Avian and Other Zoonotic). Available at: https://www.who.int/news-room/factsheets/detail/influenza-(avian-and-other-zoonotic). Accessed December 29, 2019.

41. Chen $Y$ et al., 2013. Human infections with the emerging avian influenza A H7N9 virus from wet market poultry: clinical 
analysis and characterisation of viral genome. Lancet 381 : 1916-1925.

42. Dowell SF, 2001. Seasonal variation in host susceptibility and cycles of certain infectious diseases. Emerg Infect Dis 7: 369-374.

43. Shek LP-C, Lee B-W, 2003. Epidemiology and seasonality of respiratory tract virus infections in the tropics. Paediatric Respir Rev 4: 105-111.

44. Chew FT, Doraisingham S, Ling AE, Kumarasinghe G, Lee BW, 1998. Seasonal trends of viral respiratory tract infections in the tropics. Epidemiol Infect 121: 121-128.

45. de Arruda NE et al., 1991. Acute respiratory viral infections in ambulatory children of urban northeast Brazil. $J$ Infect Dis 164: 252-258.

46. Dosseh A, Ndiaye K, Spiegel A, Sagna M, Mathiot C, 2000. Epidemiological and virological influenza survey in Dakar, Senegal: 1996-1998. Am J Trop Med Hyg 62: 639-643.

47. Chao DL, Roose A, Roh M, Kotloff KL, Proctor JL, 2019. The seasonality of diarrheal pathogens: a retrospective study of seven sites over three years. Plos Negl Trop Dis 13: e0007211.

48. Mertens A, Balakrishnan K, Ramaswamy $P$, Rajkumar $P$, Ramaprabha P, Durairaj N, Hubbard AE, Khush R, Colford JM, Arnold Benjamin F, 2019. Associations between high temperature, heavy rainfall, and diarrhea among young children in rural Tamil Nadu, India: a prospective cohort study. Environ Health Perspect 127: 047004.

49. Prottas C, Dioguardi A, Aguti S, 2018. Empowering Rural Communities to Sustain Clean Water and Improve Hygiene through Self-Help Groups. Transformation towards Sustainable and Resilient WASH Services: Proceedings of the 41st WEDC International Conference, July 9-13, 2018, Nakuru, Kenya.

50. Zafar SN, Luby SP, Mendoza C, 2010. Recall errors in a weekly survey of diarrhoea in Guatemala: determining the optimal length of recall. Epidemiol Infect 138: 264-269.
51. Arnold BF, Galiani S, Ram PK, Hubbard AE, Briceño B, Gertler PJ, Colford JM, 2013. Optimal recall period for caregiver-reported illness in risk factor and intervention studies: a multicountry study. Am J Epidemiol 177: 361-370.

52. Rothman KJ, Greenland S, Lash TL, 2008. Modern Epidemiology, 3rd edition. Philadelphia, PA: Lippincott Williams \& Wilkins.

53. Levine MM, Robins-Browne RM, 2012. Factors that explain excretion of enteric pathogens by persons without diarrhea. Clin Infect Dis 55 (Suppl 4): S303-S311.

54. Taniuchi M, Sobuz SU, Begum S, Platts-Mills JA, Liu J, Yang Z, Wang X-Q, Petri WA, Haque R, Houpt ER, 2013. Etiology of diarrhea in Bangladeshi infants in the first year of life analyzed using molecular methods. J Infect Dis 208: 1794-1802.

55. Platts-Mills JA et al., 2014. Association between stool enteropathogen quantity and disease in Tanzanian children using TaqMan array cards: a nested case-control study. Am J Trop Med Hyg 90: 133-138.

56. Humphrey $\mathrm{JH}, 2009$. Child undernutrition, tropical enteropathy, toilets, and handwashing. Lancet 374: 1032-1035.

57. Keusch GT et al., 2013. Implications of acquired environmental enteric dysfunction for growth and stunting in infants and children living in low- and middle-income countries. Food Nutr Bull 34: 357-364.

58. George CM et al., Fecal markers of environmental enteropathy are associated with animal exposure and caregiver hygiene in Bangladesh. Am J Trop Med Hyg 2015 93: 269-275.

59. Ercumen $A$ et al., 2018. Do sanitation improvements reduce fecal contamination of water, hands, food, soil, and flies? Evidence from a cluster-randomized controlled trial in rural Bangladesh. Environ Sci Technol 52: 12089-12097.

60. Prendergast AJ et al., 2019. Putting the "A" into WaSH: a call for integrated management of water, animals, sanitation, and hygiene. Lancet Planet Health 3: e336-e337. 